\title{
THE EFFECT OF SECTION SIZE ON THE MECHANICAL PROPERTIES OF WROUGHT GOLD WIRES
}

S. H. BUSH, M.S.E. AND F. A. PEYTON, D.Sc.

School of Dentistry, University of Michigan, Ann Arbor, Mich.

$\mathrm{R}^{\mathrm{B}}$ ESULTS of tensile tests made with the nonprecious metals, notably aluminum, have proved that section size is not a factor in determining proportional limit, provided the grain size is not excessive. ${ }^{1}$ However, these tests were made on specimens varying from 0.500 to 0.050 inches in diameter, and wrought dental gold wires, in which the diameter is as small as 0.030 inches, are often used. It is possible, therefore, that a similar relationship does not exist in such a case.

A survey of the technical literature indicated that no analysis had been made of the effect of section size on the mechanical properties of the dental alloys. Such data would be of interest since they might reveal the validity of applying the published values for one size wire while a different size was being used in practice.

Previous work ${ }^{2,3}$ compared chemical composition, microstructure, and such mechanical properties as Vickers' diamond pyramid hardness, tensile proportional limit in bending, ultimate tensile strength and degree of set in bending. In this report two additional factors were considered; the effect of cross section of the wires, and the influence of high temperatures during the softening process on these properties. This last test was limited to the wire least influenced by section size using the proportional limits in bending and in tension as a criterion. Tests were conducted in the softened (as quenched) as well as the hardened states in the three wires investigated.

\section{MATERIALS}

All alloys were the standard commercial products, representing the composition and property range normally met with in wrought gold dental alloys.* They were in the form available to the profession, as wrought wires with the heat treatment, if any, that is normally performed by the producer before release. The alloys were obtained as 20 gauge $(0.030$ inch $), 18$ gauge $(0.040$ inch), 16 gauge ( 0.050 inch), and 14 gauge ( 0.064 inch) wires, suitable for tensile and bend tests. The chemical compositions of the alloys are given in Table I.

\section{HEAT TREATMENT}

All alloys were heat treated before testing. The wires had apparently been heat treated by the manufacturers, and it is obvious that this previous heat

These studies were aided by a contract between the Office of Naval Research, Department of the Navy, and the University of Michigan, N6-onr-232, Task Order VIII (NR 181-360).

Received for publication March 26, 1951

Read at the meeting of the Materials Group, International Association for Dental Research, French Lick, Ind., March 18, 1951. (J. D. Res. 30: 500, 1951.)

*The three alloys investigated were supplied by the following companies:

J. M. Ney Company, Hartford, Conn., Spyco Smelting and Refining Company., Minneapolis, Minn., The S. S. White Dental Manufacturing Company., Philadelphia, Pa. 
TABLE I

Chemical Composition of Dental Gold Wires

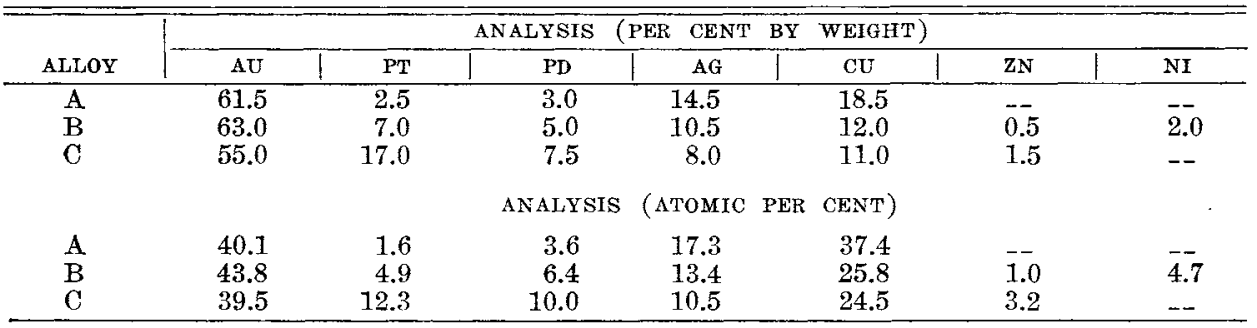

treatment could influence the results obtained, particularly where the manufacturer's heat treatment took place at a temperature greater than that used at this laboratory to insure a softened state. However, after considering these possibilities, it was believed the best procedure would be to minimize such variations as much as possible by heating all wires to $1292^{\circ} \mathrm{F}$. $\left(700^{\circ} \mathrm{C}\right.$.) for 10 minutes then quenching in water. The hardened state was obtained by reheating for 15 minutes to $680^{\circ} \mathrm{F} .\left(360^{\circ} \mathrm{C}\right.$.) in a salt bath then quenching in water. In the case of wire $C$, a further heat treatment was carried out. One series of wires was heated $1700^{\circ}$ to $1800^{\circ} \mathrm{F}$. $\left(927^{\circ}\right.$ to $982^{\circ} \mathrm{C}$.) for one hour, then water quenched. This initial set was used for a series of bend tests. A second set of wires was heated $1700^{\circ}$ to $1900^{\circ} \mathrm{F}$. $\left(927^{\circ}\right.$ to $1038^{\circ} \mathrm{C}$.) for one hour, then water quenched. The higher temperature in this case was due to lack of control on the furnace, a small laboratory type dental unit. Since the higher temperature was used solely as a qualitative measure in determining its effect on grain size and variation in mechanical properties among the different size wires, this fluctuation in temperature was not considered to be of importance.

TABLF II

Mechanical Properties of Dental Golid Wires

\begin{tabular}{|c|c|c|c|c|c|}
\hline \multirow[b]{2}{*}{ ALLOY } & \multirow{2}{*}{$\begin{array}{l}\text { WIRE } \\
\text { GAUGE }\end{array}$} & \multicolumn{2}{|c|}{$\begin{array}{l}\text { PROPORTIONAL LIMIT } \\
\text { (TENSION) }\end{array}$} & \multicolumn{2}{|c|}{$\begin{array}{l}\text { PROPORTIONAL LIMIT } \\
\text { (BENDING) }\end{array}$} \\
\hline & & SOFT & HARD & SOFT & HARD \\
\hline $\mathbf{A}$ & $\begin{array}{l}20 \\
18 \\
16 \\
14\end{array}$ & $\begin{array}{l}41,400 \\
50,900 \\
56,400 \\
55,200\end{array}$ & $\begin{array}{r}97,600 \\
100,600 \\
98,500 \\
101,800\end{array}$ & $\begin{array}{l}71,000 \\
82,100 \\
88,000 \\
88,800\end{array}$ & $\begin{array}{l}146,800 \\
156,200 \\
155,000 \\
162,500\end{array}$ \\
\hline B & $\begin{array}{l}20 \\
18 \\
16 \\
14\end{array}$ & $\begin{array}{l}47,500 \\
70,300 \\
87,900 \\
89,600\end{array}$ & $\begin{array}{l}107,600 \\
116,200 \\
123,100 \\
129,700\end{array}$ & $\begin{array}{r}96,000 \\
123,000 \\
127,300 \\
155,800\end{array}$ & $\begin{array}{l}146,300 \\
179,800 \\
194,700 \\
212,800\end{array}$ \\
\hline $\mathrm{C}$ & $\begin{array}{l}20 \\
18 \\
16 \\
14\end{array}$ & $\begin{array}{l}74,300 \\
73,900 \\
75,000 \\
73,500\end{array}$ & $\begin{array}{l}91,300 \\
93,100 \\
90,200 \\
93,900\end{array}$ & $\begin{array}{l}106,100 \\
119,400 \\
124,500 \\
121,200\end{array}$ & $\begin{array}{l}127,400 \\
148,300 \\
144,900 \\
153,900\end{array}$ \\
\hline $\mathrm{CC}$ & $\begin{array}{l}20 \\
18 \\
16 \\
14\end{array}$ & $\begin{array}{l}48,500 \\
55,500 \\
63,600 \\
59,500\end{array}$ & & $\begin{array}{r}62,000 \\
87,000 \\
103,900 \\
99,800\end{array}$ & \\
\hline
\end{tabular}


TEST PROCEDURES

Tensile and bend tests as well as hardness measurements and polishing techniques were performed in the manner discussed in previous reports. ${ }^{2,3} \mathrm{~A}$ Tinius Olsen mechanical drive machine was used for the tensile tests. Bend tests were made on a Tinius Olsen stiffness tester using 2-inch wire lengths, and hardnesses were determined with a Vickers hardness tester using a $10 \mathrm{~kg}$. load and a $136^{\circ}$ diamond pyramid point.

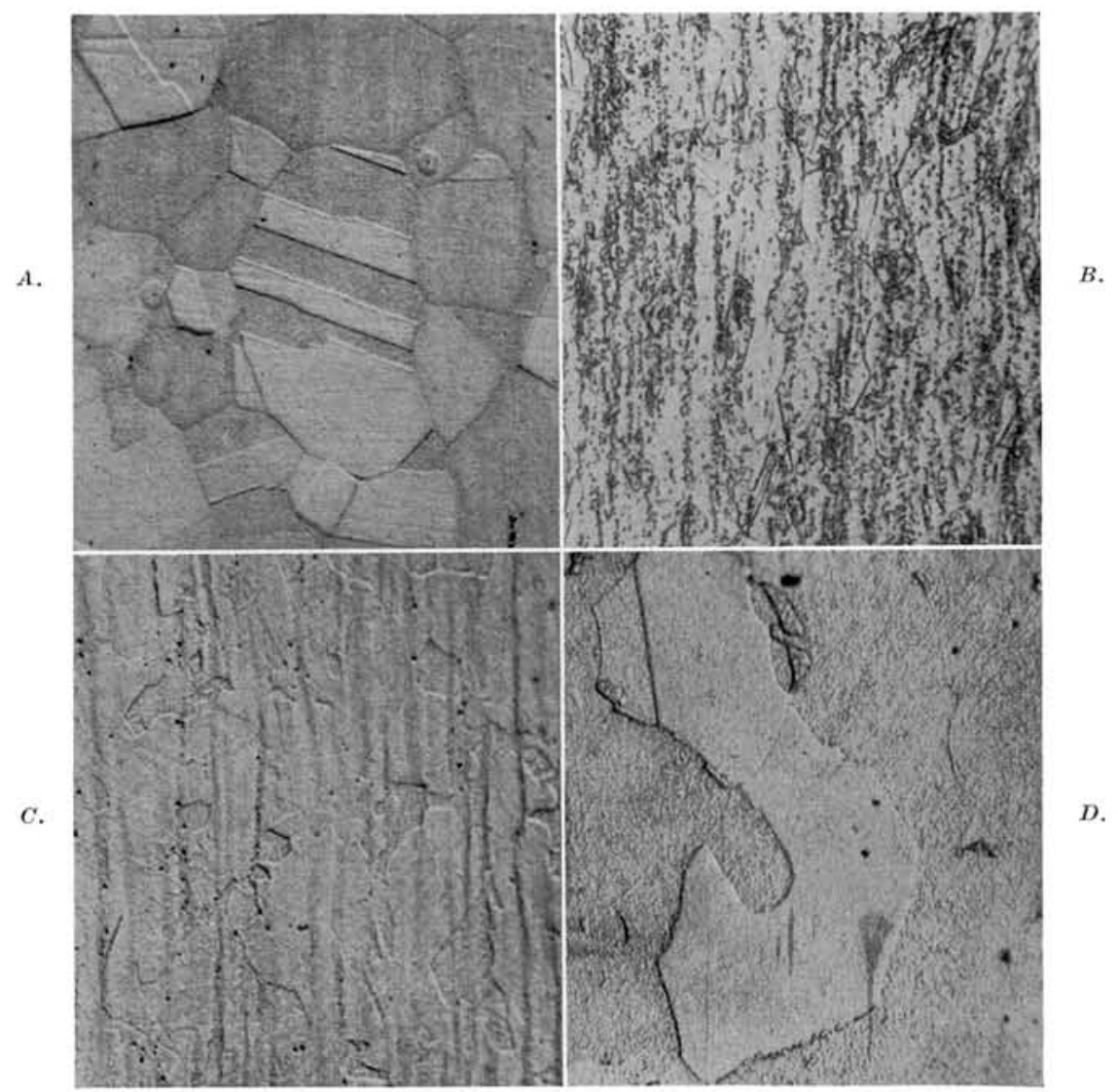

Fig. 1.-Microstructures of wrought gold wires. Potassium cyanide-Ammonium Persulfate Etch. 1000 diameters. $A$, Alloy $A$, soft. $B$, Alloy $B$, soft. $C$, Alloy $C$, soft. $D$, Alloy $C C$.

\section{RESULTS}

Proportional limit in bending and in tension was selected as a criterion for comparison, and these are the only values tabulated in Table II.

The microstructures of the three alloys are given at 1000 diameters in Fig. 1 in the soft (as quenched) state. An additional microstructure is also given in Fig. 1. This illustrates the effect on the grain size of alloy $C$ of heating 


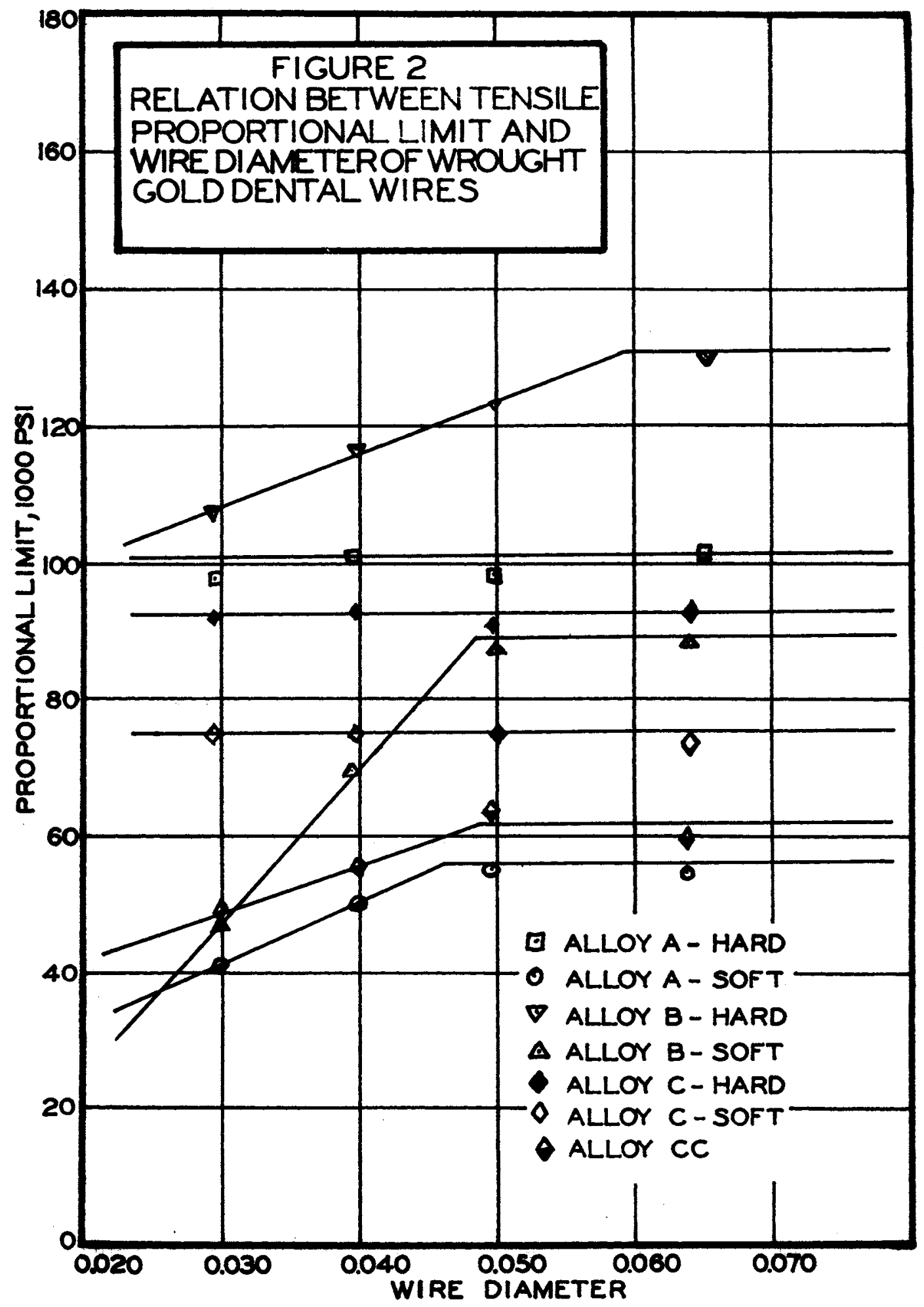




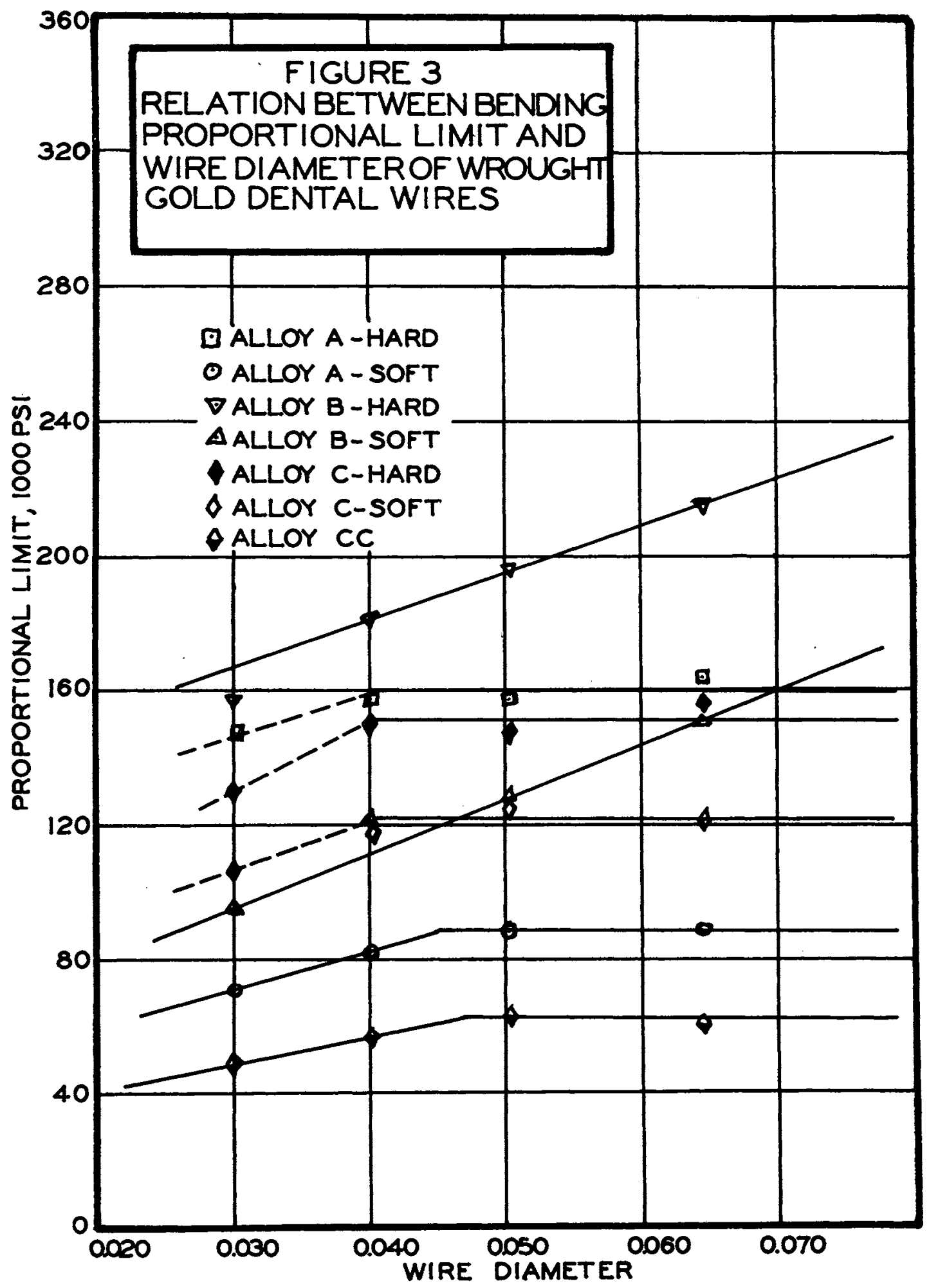


to $1700^{\circ}$ to $1800^{\circ} \mathrm{F}$. for one hour. The photomicrographs aid in predicting the effect of grain size on the mechanical properties of wires as a function of the section size.

The difference in grain size from alloy to alloy, as well as that occurring in one particular alloy due to a variation in the heat treatment, is sufficient to infer qualitatively the existence of a critical section size below which the proportional limits decrease with a decrease in diameter. Above this eritical cross section no change in mechanical properties should be noted with an increasing diameter.

\section{DISCUSSION}

In Figs. 2 and 3 are plotted the proportional limit in tension and proportional limit in bending versus the wire diameter, definitely indicating that no correlation exists between these mechanical properties and the section size of the wire. Examination of Fig. 2, proportional limit in tension versus wire diameter, does indicate that the different alloys, after the manufacturer's heat treatment and the softening heat treatment, did not respond in the same fashion. Alloy $A$ has a critical diameter of about 0.044 inch, below which the proportional limit decreases with a decrease in diameter, and above which no change occurs with an increase in diameter. Alloy $B$ responds in a similar fashion. In this case the critical diameter occurs at 0.048 inch. Alloy $C$, however, has a critical diameter less than that of the smallest wire tested $(0.030$ inch $)$ since there is no change in proportional limit noted from the largest to the smallest wire. To determine the effect of excessively high heat treatment temperatures on an alloy, the least responsive, $C$, was heated within a temperature range varying from $1700^{\circ}$ to $1900^{\circ} \mathrm{F}$. and held there for one hour before being quenched in water. These tests, designated by the code letters $C C$, had lower proportional limits, a higher critical diameter (0.048 inch), and an increased grain size.

An examination of the proportional limits in tension as a function of the diameter indicates that the wires are generally less structure-sensitive in the hardened than in the softened state. Alloy $A$ apparently has a critical section size slightly greater than or, possibly, less than 0.030 inch. Alloy $C$ responds in the same fashion. The response of Alloy $B$ differs from that of the other two. The results indicate that the critical section size is definitely increased. It is not possible to tell whether it is greater than 0.064 inch, but it cannot be much less in any event. No adequate explanation of this phenomenon is advanced due to lack of sufficient data; however, it is suggested that the precipitation hardening which is so pronounced in this particular alloy may be partially responsible.

The results of proportional limit in bending versus wire diameter are shown in Fig. 3. Analysis of the alloys in the softened state indicates that the results are comparable to those obtained in the tensile tests. In Alloy $A$ the eritical diameter is 0.045 inch. Apparently Alloy $B$ is more structure-sensitive in bending than in tension, since the critical diameter is greater than 0.064 inch. Alloy $C$ is also slightly more structure-sensitive. In tension the critical diameter 
was less than $0.030 \mathrm{inch}$. In bending the critical diameter is approximately 0.040 inch. Alloy $C C$ has a greater critical diameter than Alloy $C$, as would be expected. Here, the critical diameter is 0.046 inch.

The hardened wires again responded in bending in a fashion similar to that observed in the tensile tests. Alloy $A$ had a critical diameter between 0.030 inch and 0.040 inch, somewhat higher than was observed in the tensile results. Alloy $C$ also fell in this same range, again higher than in the tensile tests. In the case of Alloy $B$ the critical diameter was greater than 0.064 inch, duplicating the results of the tensile tests.

It is apparent that either tensile or bend tests are satisfactory for determining the critical section size. In some cases the slightly greater sensitivity noted at smaller diameters, when using the bend test, indicates it might be preferable, particularly since the test condition is more comparable to conditions in practice than is a tensile test.

A comparison of the photomicrographs in Fig. 1 indicates that grain size is not the sole factor in determining the critical diameter. This is understandable when the wide variation in chemical composition is noted together with the definite over-all difference in shape of grain and type of precipitate occurring in the various alloys. In Alloy $C$, where such variables as chemical composition and type of matrix precipitate are eliminated, the increase in grain size accompanying the heat treatment at an excessive temperature can be considered to be one of the most important factors in shifting the critical diameter upward. It probably is not the sole factor, but it undoubtedly is responsible for some of the decrease in the proportional limit and the shift in critical section size.

\section{CONCLUSIONS}

1. No definite correlation exists between cross-section of the wire in either the soft or hard state and proportional limit in bending or in tension.

2. A critical section size exists below which the mechanical proporties change as the section size decreases, and above which, no change in mechanical properties is noted with an increase in section size.

3. An increase in the platinum content is accompanied by a decrease in the critical section size. This is attributed to the refinement in grain size which accompanies such an increase in platinum.

4. An alloy with a small grain size is less structure-sensitive than an alloy with a large grain size. In the same alloy an increase in grain size is accompanied by a similar increase in the critical section size.

5. If the wires are heat-treated at an excessively high temperature, an increase in the grain size, and a decrease in the proportional limits in bending and in tension, will occur together with an increase in the critical section size. provided, of course, that the wires have not been subjected to a previous heat treatment at a higher temperature.

6. Both tensile and bend tests are satisfactory for determining the critical section size in hard or soft wires; however, the results indicate that the bend test may have a greater degree of section sensitivity than the tensile tests, at least in certain alloys. 
7. Published values of the proportional limits of various alloys, when based on a single wire diameter, should be used for design purposes only when the design structure is equal to or greater in cross-section than the cross-section of the test wire. This precaution is unnecessary if it is known that the critical cross-section is smaller than either the design or test wire cross-section.

8. Alloys in which a pronounced precipitation hardening occurs are apparently much more structure sensitive in the hardened than in the softened state. On hardening, the eritical section size is shifted to a much greater value in both tensile and bend tests.

\section{REFERENCES}

1. Templin, R. I., and Aber, W. C.: A Method for Making Tension Tests of Metals Using a Miniature Specimen, A. S. T. M. Preprint, 1950.

2. Taylor, D. F., and Peyton, F. A.: A Comparison of the Tensile and Bending Properties of Dental Gold Wires, J. D. Res. 30: 290, 1951.

3. Bush, S. H., Taylor, D. F., and Peyton, F. A.: A Comparison of the Mechanical Properties, Chemical Compositions, and Microstructures of Dental Gold Wires, J. Pros. Dent. 1: $177,1951$.

\section{Errata}

In Abstract 18 (J.D. Res. 30:465, 1951), line 7 on page 466 should read "The precarious lesions," not "The carious lesions.",

In Abstract 121 (J.D. Res. 30: 504, 1951), line 2 on page 505 should read "erupted tooth," and not "unerupted tooth.", 